\title{
ADVERSE EFFECTS OF ANTIOXIDATIVE VITAMINS
}

\section{MACIEJ RUTKOWSKI ${ }^{1}$ and KRZYSZTOF GRZEGORCZYK ${ }^{2}$}

\author{
${ }^{1}$ Medical University of Łódź, Łódź, Poland \\ Department of Clinical Chemistry and Biochemistry \\ ${ }^{2}$ Wł. Biegański Memorial Regional Specialistic Hospital, Łódź, Poland \\ Department of Endoscopy and One Day Gastroenterology
}

\begin{abstract}
High doses of synthetic antioxidative vitamins: A, E, C and $\beta$-carotene are often used on long-term basis in numerous preventive and therapeutic medical applications. Instead of expected health effects, the use of those vitamins may however lead to cases of hypervitaminosis and even to intoxication. The article points out main principles of safety which are to be observed during supplementation with antioxidative vitamins. Toxic effects resulting from erroneous administration of high doses of those substances on organs and systems of the organism are also discussed. Attention is drawn to interactions of antioxidative vitamins with concomitantly used drugs, as well as intensification of adverse effects caused by various exogenous chemical factors. Moreover, the article presents the evaluation of supplementation with these vitamins, which was performed in large studies.
\end{abstract}

Key words:

Vitamins A, E and C, $\beta$-carotene, Supplementation, Side actions, Toxic effects

\section{INTRODUCTION}

Supplementation with synthetic antioxidative vitamins: A, $\beta$-carotene (provitamin A), E and $\mathrm{C}$, is widely propagated to-day, both as an adjunct to the applied pharmacotherapy and as one of factors to provide "health and beauty". Common use of additional intake of the above mentioned supplements is well-known [1,2].

Such popularised usage of antioxidative vitamins stems mainly from the fact they are treated as natural substances (even though today they are mostly products of organic synthesis) and regarded as safe and free from any significant toxicity. That is why they do not have pharmaceutical status of medicines, but are included only among auxiliary agents as "dietary supplements". As a result, they are not subject to any rigorous safety tests specific for pharmaceutical drugs, and their preparations are generally sold over the counter. However, it is commonly disregarded that the excessive intake of antioxidative vitamins may be in fact harmful. Enthusiasts of at-home vitamin supplementation, who blindly believe in newspaper revelations and advertisements, are therefore vulnerable to overdose and - as a result - may experience concealed adverse effects.

The problem of those effects emerged on a large scale during medical trials of vitamin supplementation, after discovering the disorders of oxygenic metabolism in pathogenesis of numerous diseases and introducing vitamins $\mathrm{A}, \mathrm{E} \mathrm{C}$ and $\beta$-carotene as antioxidants in adjunctive therapy. In order to achieve the assumed efficiency of antioxidative effects, these vitamins were applied on long-term basis in arbitrarily set high doses [3-6]

Received: October 7, 2010. Accepted: March 7, 2012.

Address reprint request to K. Grzegorczyk, Department of Endoscopy and One Day Gastroenterology, Wł. Biegański Memorial Regional Specialistic Hospital, Kniaziewicza 1/5, 91-347 Łódź, Poland (e-mail: krzysztofgrzegorczyk1@wp.pl). 
in accordance with the motto "more means better". As a result, their bodily concentrations many times exceeded the physiological values. Large-scale research testing the effectiveness of such vitamin supplementation revealed, however, that in most cases the hopes were not fulfilled, while - surprisingly enough - multiple adverse effects appeared. Therefore, authors of some publications started to warn against supplementation conducted in this way [e.g. 7].

Data on adverse effects of antioxidative vitamins, so important for the safety of planned supplementation trials on selected groups of patients, are dispersed in literature and very often fragmentary or only superficial (as was already noted by some other authors [8,9]). This is the rationale behind this article - its aim is to gather and systematise possibly the most complete data to present the current state of knowledge. We hope this article will go a long way towards paying more attention to the discussed and sometimes overlooked issues connected with vitamin therapy - nowadays common, but often applied without due prudence.

To proceed with our discussion, please note that the data presented below is based on various isolated and often incidental observations. Only few data come from fragmentary research on animals (tests of vitamins $\mathrm{A}$ and $\mathrm{E}$ on pregnant rats) or healthy volunteers (tests on the influence of high doses of vitamin $\mathrm{C}$ on the state of health). Information on acute vitamin $\mathrm{A}$ toxicity was provided by incidents of unintentional intake of excessive amount of this vitamin. Other highly harmful effects were consequences of random mistakes in medically applied doses of particular vitamins. Data regarding chronic outcomes was gathered as a side effect of a long-term supplementation with antioxidative vitamins, applied in diseases described in the text below. The authors used also some information adduced by the quoted vitamin experts.

\section{VITAMIN A}

\section{Biomedical action}

Vitamin A (retinol) performs many important physiological functions in human body [1,2]. It accelerates the synthesis of collagen and elastin fibres by fibroblasts, as well as the processes of cell division, thanks to which it stimulates growth of foetus and young organisms. It ensures proper proliferation and differentiation of epithelial cells, contributing also to their regeneration and, owing to this, it significantly influences proper functioning of skin and mucous membranes. Vitamin A positively influences the development of skeleton by regulating activities of osteoblasts and osteoclasts. It participates in hormonal regulation of the body by decreasing secretion of thyroxin (one of thyroid hormones) by means of suppressing production of thyrotropin by the pituitary gland. It is also essential for the process of seeing, as it is needed (in a form of 11-cisretinal) for synthesis of rhodopsin, also known as visual purple, in the retina of the eye $[2,10]$. Furthermore, vitamin A stimulates functioning of the immune system in the body and increases its resistance to infections [11].

A vital property of vitamin A is also its antioxidative action, including both prevention against reactive oxygen species (ROS) and termination of reactions taking place with their participation [12-14]. Very crucial is this vitamin's ability to quench singlet oxygen ${ }^{1} \mathrm{O}_{2}$, as well as trap and neutralize free radicals $[12,15]$. The above described action arises from the presence of the conjugated $\mathrm{C}=\mathrm{C}$ bonds in the side chains of its molecules. These bonds compete in addition reactions of ROS and free radicals to polyunsaturated fatty acids contained in lipids of cell membranes, and in this way protect the cells against peroxidative damage. At the same time vitamin A suppresses the activity of enzymes participating in propagation of peroxidation of these lipids, as well as prevents oxidative disorders of protein glycosylation in cell membranes $[13,14]$. The presented antioxidative mechanisms have their significant contribution to the previously mentioned impact 
of vitamin A on proliferation and differentiation of epithelial cells, as they prevent their neoplastic transformation (promotion stage) induced by processes of uncontrolled oxidation. This concerns especially incorrect glycosylation of proteins in cell membranes, which influences their surface properties - transformed cells have fewer surface glycoproteins than regular ones [16-18]. Vitamin A stabilizes also thiol groups $(-\mathrm{SH})$ of membrane proteins and suppresses oxidatively stimulated expression of c-myc oncogene on chromosome 8. It enables also the recovery of intracellular communications via the already transformed cells $[16,18]$. Due to the fact that around $90 \%$ of neoplasms are developed in epithelial tissues, the discussed vitamin has particular significance for these tissues in terms of its preventative and suppressive effect [17-19]. This concerns various parts of the body containing epithelial tissues, including: nasal and throat cavity, oesophagus, stomach, intestines, respiratory tract, bladder, as well as prostate (suppression of its overgrowth).

\section{Potential risk}

Therapeutic intake of large amounts of vitamin A, exceeding the limited storage capacity of the liver, may lead to the supersaturation of the body with this vitamin and the poisoning referred to as hypervitaminosis $\mathrm{A}$ - the blood concentration of the a/m vitamin $>1.0 \mathrm{mg} / \mathrm{l}(3.5 \mu \mathrm{mol} / \mathrm{l})$ is indicative of that condition [20,21]. Toxic effects appear when the ability of plasma RBP (retinol binding protein the carrier for vitamin A in blood) to bind retinol and to conjugate its excess with glucuronate is exceeded, which leads to harmful exposure of the cells to free vitamin A $[14,22,23]$. Patients with hepatic and renal diseases and children are especially susceptible to the adverse effects of this vitamin. The supplementation with provitamin A, i.e. $\beta$-carotene, is safer $[2,24]$.

Hypervitaminosis A can take the form of acute or chronic poisoning. The first of these two forms appears after the intake of 150-1200 mg (in International Units: 500 000-4000000 IU) of vitamin A over two days by adults, after the single dose about of $45 \mathrm{mg}$ (150 $000 \mathrm{IU})$ by school-age children, or after the intake about of $22 \mathrm{mg}$ (75000 IU) by small children. This kind of poisoning appeared, for example, in preschool children (supplemented with this vitamin for prevention against nyctalopia), who were mistakenly given in single doses as much as $500000 \mathrm{IU}$ of vitamin A. As a result, over 20 of these children died [25]. An extreme case was a fatal poisoning of polar explorers after the consumption of polar bear liver (where vitamin A content is approx. $10 \mathrm{mg} / \mathrm{g}$ ) [3,26,27]. The chronic poisoning results from the long-term intake of this vitamin (ranging from several weeks to more than 3 years) at the doses $>30 \mathrm{mg}(100000 \mathrm{IU}) / \mathrm{d}$ by adults, or for 2 to 6 months at the doses of 3-9 mg (10 000-30 $000 \mathrm{IU}) / \mathrm{d}$ by children, and for 1-3 months at the dose of $3 \mathrm{mg}$ (10 $000 \mathrm{IU}) / \mathrm{d}$ by infants.

The symptoms of acute poisoning are: general weakness, dizziness and a severe headache (in the occipital part), an increase in intracranial pressure, nausea, vomiting, sitophobia, hepatosplenomegalia, and after a few days, skin changes (itching, erythema, and desquamation). The chronic poisoning symptoms include: feeling of chronic fatigue, irritability, double vision, nystagmus, sleep disturbances, cracking and bleeding lips and gums, shedding of hair, rashes and ulceration of the skin, muscular coordination disturbances, renal dysfunction (haematuria), and even oedema of the optic disc and other symptoms that could suggest a brain tumor. Hypervitaminosis A can also lead to auditory sensations which are not caused by any sound stimulus (parestesia) [22,23,28,29].

The excessive intake of vitamin A affects harmfully the haematopoietic system, leading to aplastic anemia. It accelerates erythrocyte sedimentation rate and prolongs the prothrombin time. It also causes leukopaenia, weakening at the same time the defense ability of the body [14,24,27]. Another consequence of the excessive supply of vitamin A 
is the disruption of absorption of $\beta$-carotene and mineral salts from food [1,14].

Taking excessive amounts of vitamin A is also harmful for the osteoarticular system. It leads to joint and spine pains, as well as decalcification of bones (with the increase of calcium concentration in blood), which causes their brittleness and increases the risk of osteoporosis, and - as a result - also femoral neck fractures [30,31]. Some researchers have posited also that another result of vitamin A overdose is the decrease of bone mineral density (BMD). In a Swedish research [32] it was found out that the effect of the four-year intake of the discussed vitamin by women at doses $>1.5 \mathrm{mg}$ (5000 IU) per day was a decrease of BMD by: $10 \%$ at the femoral neck, $13 \%$ at the Ward triangle, $9 \%$ at the trochanter region of the proximal femur, $14 \%$ at the lumbar spine, and $6 \%$ for the total body. Similar results were achieved in the United States [33], where it was also noted that the decrease of BMD appeared both in women (W) and men (M), annually amounting to: at the hip $1.6 \%(\mathrm{~W}), 1.2 \%(\mathrm{M})$; at the femoral neck $2 \%(\mathrm{~W})$, $1.4 \%(\mathrm{M})$; at the spine $1.3 \%(\mathrm{~W}), 1.2 \%(\mathrm{M})$. However, another research from the US [34] did not reveal any connection between high concentrations of vitamin $\mathrm{A}$ in blood and the decrease of BMD.

The adverse effects of vitamin A recede after its withdrawal or the decrease in the applied dose (in children, however, growth inhibition may occur, as a result of premature ossification of the epiphyses of long bones) [28,29]. The above-mentioned effects are exacerbated by alcohol consumption [35].

High doses of vitamin A must not be administered in liver failure and cirrhosis or in bile ducts obstruction, due to the increase in the risk of toxic effects described above [20,26,36]. These high doses should be avoided during pregnancy, due to their contribution to fetal development anomalies (teratogenic activity). Pregnant women should not take more than approx. $2 \mathrm{mg}$ (6000 IU) of this vitamin D (including its content in nourishment) and it should be administered under strict medical control (it is advisable to eliminate animal liver from the diet) [3,37,38]. High-dose vitamin A therapy in breast-feeding women, which could cause symptoms of hypervitaminosis in infants, is contraindicated [20,21].

Many dose-dependent, adverse effects are also caused by synthetic retinoids (e.g. by isotretinoin) [29]. These potentiate the action of vitamin A and hence should not be administered during this high-dose vitamin therapy. Synthetic retinoids irritate skin and mucosa, causing erythema, rash, contact dermatitis and loss of hair, and exacerbate the symptoms in patients with psoriasis. They impair liver functions, what may be manifested in blood by increased activities of various enzymes, e.g. ALAT (alanine aminotransferase), AspAT (aspartate aminotransferase) and LDH (lactate dehydrogenase), increased lipid profile with the decrease of the level of HDL (high-density lipoprotein), as well as increased concentrations of metabolites such as bilirubin and uric acid. The resultant toxic effects disrupt also composition and properties of the blood itself, leading to anaemia, neutropenia, acceleration of erythrocyte sedimentation rate (ESR) and coagulability disorders. Like vitamin A, synthetic retinoids increase the risk of osteoporosis. Also, they show embryotoxic and teratogenic activity, so they must not be used during pregnancy and lactation, even at low doses [23,30,31,37,38].

\section{$\beta$-CAROTENE}

\section{Biomedical action}

In the human body, $\beta$-carotene supports intercellular communication, inhibits proliferation of cells and modulates their differentiating. It also strengthens immune system, among others by activating interferons $[39,40]$. Part of $\beta$-carotene stored in the fatty tissue plays the role of stock form of vitamin A and in case of deficiencies can be cleaved into this vitamin [41]. 
Except these physiological functions, owing to the polyene's molecular structure, $\beta$-carotene demonstrates an effective antioxidative action. Just like vitamin A it quenches ${ }^{1} \mathrm{O}_{2}$, as well as traps and neutralizes various free radicals $[40,42]$. Besides, $\beta$-carotene deactivates the earlier formed peroxy radicals of the body's lipids, preventing their propagation and participation in peroxidative processes. Therefore, its action involves prevention and termination of the course of ROS-mediated reactions $[12,15,43]$. What is especially important, $\beta$-carotene is antioxidatively active in low oxygen partial pressure $\left(\mathrm{pO}_{2}\right)$ that is prevalent in peripheral tissues, and in this way it completes the further described antioxidative effects of vitamin $\mathrm{E}$, which are strongest for the highest values of $\mathrm{pO}_{2}$ (in pulmonary alveoli) $[40,43]$.

As a result of the above mentioned reactions, $\beta$-carotene effectively participates in prevention of the oxidative stress - that is the shifting of the pro-/antioxidative systemic balance towards the processes of oxidation. It is used so in prevention and therapy of many diseases developing with participation of this stress, mainly neoplasms and cardiovascular abnormalities [36,44-46].

\section{Potential risk}

For a long time $\beta$-carotene, considered only as provitamin A, was believed to be practically harmless. It was stressed that its enzymatic conversion to retinol (in liver and small intestine wall), thanks to homeostatic control, provided only as much vitamin $\mathrm{A}$ as required by the body due to a temporary deficiency, and that $\beta$-carotene excess was expelled in faeces [41,47]. This opinion was confirmed by an observation that even a long-standing supplementation with $\beta$-carotene $(25 \mathrm{mg} / \mathrm{d})$ did not cause hypervitaminosis A with its effects as described above, provided that no preparations of vitamin A were taken at the same time $[6,21,48]$.

Research has shown that $\beta$-carotene is not embryotoxic, mutagenic or carcinogenic [49]. One harmless result of its prolonged intake in large doses is a yellowish skin tinge, known as carotenemia. This is caused by deposition of $\beta$-carotene in the subcutaneous fatty tissue and recedes within a few days after decreasing the dose. Especially susceptible to this condition are people with hyperthyroidism, cirrhosis, hypercholesterolemia, diabetes and nephrosis (this discolouration is different from jaundice because of no yellow tinge of sclera) $[2,29,40]$. Another harmless consequence of supplementation with $\beta$-carotene may be slight diarrhoea which, however, may affect only those people who are oversensitive to this substance due to an innate metabolic defect [50].

In view of the data presented above that $\beta$-carotene does not cause any significant health threats, the effect of supplementation with this substance $(20 \mathrm{mg} / \mathrm{d})$ in smokers was surprising, with $18 \%$-increase in lung cancer incidence and the increased mortality caused by this compound [51-54]. Similar results were noted for the supplementation of patients occupationally exposed to asbestos [39,55]. An increase in the frequency of intracerebral haemorrhage cases in supplemented alcoholics was also found [36]. These facts lead to the conclusion that cigarette smoke, asbestos and alcohol, which all exacerbate oxidative stress [15], contribute to the prooxidant activity of $\beta$-carotene, potentiating the damage to body cells $[28,35,42,49]$. It indicates that $\beta$-carotene, which was antioxidatively active at low $\mathrm{pO}_{2}$, at high values of $\mathrm{pO}_{2}$ was not only antioxidatively passive, but became a prooxidant $[39,42,43]$. Betacarotene can even lead to the increase in DNA (deoxyribonucleic acid) damage when its concentration reaches about $5.5 \mathrm{mg} / \mathrm{l}(10 \mu \mathrm{mol} / \mathrm{l})$, which results in the loss of its activity characteristic of low concentrations protecting the cells from DNA damage [39,50].

The products of $\beta$-carotene reactions with ROS and free oxygen radicals formed in the organisms of people exposed to oxidative stress and supplemented with that compound also contribute to prooxidant effects. The majority of those products are prooxidants and they cause 
cellular damage or can be even carcinogenic during selective supplementation with $\beta$-carotene [22,40,49]. In turn, $\beta$-apo-carotenals, formed from peroxide radical-induced asymmetric breakdown of $\beta$-carotene, produce specific isoforms of cytochrome P-450 which convert procarcinogens present in the cigarette smoke into ultimate carcinogens, thereby enhancing progression of lung neoplasms in smokers. Those effects are eliminated by the parallel administration of vitamin $\mathrm{E}$, which prevents $\beta$-apo-carotenal generation [43,54].

Selective supplementation with $\beta$-carotene also affects the content of various other antioxidants in the organism. The intake of $\beta$-carotene at high doses increases plasma concentrations of $\alpha$-carotene, lycopene and vitamin $E$, and decreases simultaneously luthein and zeaxanthin concentrations $[28,40,56]$.

\section{VITAMIN E}

\section{Biomedical action}

Vitamin E has eight forms: four tocopherols $(\alpha, \beta, \gamma, \delta)$ and four tocotrienols (also $\alpha, \beta, \gamma, \delta$ ), while $\alpha$-tocopherol constitutes some $90 \%$ of them and shows also the strongest biological activity [57,58]. The terms $\alpha$-tocopherol and vitamin $\mathrm{E}$ are often used alternatively. The latter term has been used in this sense in subsequent chapters of this text.

The physiological functions of vitamin E comprise: stimulation of fertility (including prevention of miscarriages), participation in biosynthesis of collagen (crucial for the proper structure of muscles and walls of blood vessels), as well as activation of immune system [1,2,58]. Vitamin E participates also in tissue respiration as it may substitute for ubiquinones in electron transport $[1,15]$.

Vitamin E acts also as an antioxidant and deactivates ROS, including ${ }^{1} \mathrm{O}_{2}, \mathrm{O}_{2}{ }^{--}$(superoxide radical anion) and $\cdot \mathrm{OH}$ (hydroxyl radical). However, this is true only about the free, i.e. non-esterified vitamin E [59,60], while the majority of its preparations contain $\alpha$-tocopherol acetate. The antioxidative action of vitamin $\mathrm{E}$ is mostly directed at lipids of cellular membranes, protecting them at the stage of prevention and termination against ROS-mediated reactions, which generate peroxides acting as the secondary ROS. Vitamin E also regenerates the antioxidatively used up $\beta$-carotene and protects vitamin A against oxidation [12,13,59]. Generally it plays such an important role in oxidative stress counteraction that it is considered to be the main lipophilic antioxidant of the body $[59,60]$.

Because of these properties, the synthetic vitamin E is applied as an antioxidant in prevention and support treatment of various diseases involving defects in oxygenic metabolism, usually combined also with other antioxidants. In the above mentioned applications, patients are given high doses of this vitamin of several hundreds $\mathrm{mg} / \mathrm{d}$, which many times exceed the RDA (Recommended Dietary Allowance) values [36,45,59,61,62].

\section{Potential risk}

The synthetic vitamin E doses used in antioxidant therapy may arouse justified concerns because, for example in the United States, $300 \mathrm{mg} / \mathrm{d}$ is the maximum tolerated daily dose of this vitamin, and $2 \mathrm{~g} / \mathrm{d}$ is already considered to be toxic $[5,21,24,48]$. In fact, the data coming from popular handbooks and lexicons about good tolerance of this vitamin and no hypervitaminosis or toxic effects, refer to its classic (i.e. non-antioxidant) applications and thus the doses not much exceeding the daily requirements.

Vitamin E is only seemingly safe, i.e. moderately nontoxic compared with vitamins A or D $[22,63]$. When used at high doses, it can lead to harmful effects (mainly during injections) due to the inhibition of 5-lipoxygenase in blood platelets and leucocytes (which results in insufficient synthesis of thromboxane and leucotrienes), decreased blood coagulability (resulting from the excessive suppression of platelet aggregation), and disruption of granulocyte and 
phagocyte anti-infective function based on the generation of “useful” ROS [23,59,64].

In the case of too low systemic concentrations of $\alpha$-tocopheryl radical-regenerating substances, large received doses of vitamin $\mathrm{E}$ act prooxidatively [65]. They cause excessive generation of those radicals which initiate lipid peroxidation in cellular membranes and LDL (lowdensity lipoproteins) $[15,44,59,61]$ - the bodily structures which bind the above vitamin. Such doses may amplify ROS generation in the presence of iron and copper $[24,28,66]$.

High doses of vitamin $\mathrm{E}$ decrease systemic vitamin A stores [29], and, when administered in the $\alpha$-tocopherol or its acetate form, they limit the dietary absorption of therapeutically important $\gamma$-tocopherol, present only in the diet [57,67]. Vitamin E anticoagulant activity causes its antagonism with vitamin $\mathrm{K}$, which can lead to bleeding when the latter is deficient, especially in patients treated with anticoagulants (e.g. with acenocoumarol or warfarin) or estrogens - both groups should not be given more than $40 \mathrm{mg} / \mathrm{d}$ of vitamin E [28,56,64].

The harmful effects of vitamin E were also observed after it had been applied in the therapy of coronary artery disease treated with synvastatin and niacin (i.e. nicotinic acid or vitamin PP). As a result, attenuation of those two lipid disturbance-correcting drug-mediated positive effects was noted along with atherosclerosis progression in the coronary vessels [68].

The adverse effects of vitamin E were confirmed in the longterm intake of this substance at doses over $240-480 \mathrm{mg} / \mathrm{d}$ $[21,24]$. These include the so-called influenza symptoms and also the alimentary tract symptoms (gastric pain, vomiting and diarrhea), muscular weakness, skin inflammations and rashes; more severe forms include double vision, liver enlargement, sexual dysfunction, hyperglycemia and hyperlipidemia $[22,23,29]$. These symptoms generally subside shortly after reduction of the doses. It is should be emphasized that the above described harmful effects of long-term antioxidative therapy with use of high doses of vitamin $\mathrm{E}$ are not inevitable. For example they were not observed in patients who were subject to such treatment in disease cases mentioned in the last part of this article.

Special caution is necessary, however, when applying this vitamin to neonates and babies. For them, the safe dose is only $2.8-3.5 \mathrm{mg} / \mathrm{kg} \mathrm{BM}$ (there were cases of deaths of premature infants caused by liver damages after oxygen therapy, when vitamin E was applied at $20 \mathrm{mg} / \mathrm{kg} \mathrm{BM}$ for protection of their alveoli, lenses and retina against ROS intensively generated in these conditions [69]). Large doses of vitamin $\mathrm{E}$ are also not recommended in pregnant and breast-feeding women, due to lack of safety data $[1,5,21,48]$. Other groups of people can be given large doses of this vitamin, but with concomitant monitoring of its plasma concentration along with vitamin A, total lipids and iron concentrations (monitoring of vitamin $\mathrm{C}$, selenium, and total cholesterol would be also advantageous) $[57,59,63]$. This is the prerequisite for treatment efficacy and will protect from the development of adverse effects.

\section{VITAMIN C}

\section{Biomedical action}

Physiological functions of vitamin C (L-ascorbic acid) include participation in hydroxylation reactions while producing: hydroxyproline and hydroxylysine (crucial for production of collagen), tyrosine, noradrenalin and serotonin, as well as L-carnitine, steroid hormones of the adrenal glands and bile acids $[1,70,71]$. As a reducer, it participates in biosynthesis of tetrahydrofolic acid, hyaluronic acid and prostaglandins [2,70]. It also modulates the body's immunity by stimulating the production of immunoglobulins and interferons $[1,70]$.

Vitamin C is easily and reversibly oxidized into dehydroL-ascorbic acid, creating a redox system with the potential of $0.08 \mathrm{~V}$, which allows it to act as an antioxidant. 
It deactivates multiple ROS: ${ }^{1} \mathrm{O}_{2}, \mathrm{O}_{2}{ }^{\cdot-}, \cdot \mathrm{OH}, \mathrm{H}_{2} \mathrm{O}_{2}$ (hydrogen peroxide), $\mathrm{HO}_{2}{ }^{\circ}$ (hydroperoxyl radical) as well as peroxides and free radicals produced with their participation $[12,15,72,73]$. Thanks to this it prevents reactions of these ROS with biomolecules at the stage of prevention, termination and even repair of some damages. It also regenerates vitamin $\mathrm{E}$ used up during similar processes [71-74]. Thus, vitamin $\mathrm{C}$ plays an important role in eliminating oxidative stress which, in combination with its water solubility, makes it the main antioxidant of extracellular fluids [46,71].

The above described processes constitute grounds for using vitamin $\mathrm{C}$ in prevention and therapy of diseases resulting from, or occurring with, oxidative stress. These are the diseases listed in the description of vitamin $\mathrm{E}$ (both vitamins cooperate with each other [74]) and additionally also cataract, rheumatoid arthritis, accelerated ageing syndrome and others $[4,18,45,72,75]$. Vitamin $\mathrm{C}$ also takes part in detoxification of xenobiotics contributing to the production of ROS [76].

\section{Potential risk}

Vitamin C is practically nontoxic [22-24], however, its large doses $(500 \mathrm{mg} / \mathrm{d}$ or more) can cause alimentary tract disturbances (nausea, pyrosis and diarrhea), enhanced urination with a feeling of burning, and also erythrocyte hemolysis during glucose-6-phosphate dehydrogenase (G-6-PD) and vitamin $\mathrm{B}_{12}$ deficiency $[4,77]$. By inducing severe urine acidification, such doses impair the excretion of weak acids and bases, which may result in the precipitation of cystinate and urate depositions in the urinary tract, leading to the formation of renal calculi [29,73,78,79]. Vitamin C doses > 1g/d elevate blood and urinary oxalic acid concentrations to a degree increasing the risk of calculi formation from calcium oxalate $[2,79,80]$. Thus, such large doses should not be administered in chronic renal failure, cystinuria, predisposition to gout, urate and oxalate calculosis.
Therapeutically applied vitamin C increases blood sodium concentration and decreases potassium concentration which can lead to deficiency of the latter [21,73]. Also, it negatively impacts on some drugs taken, causing vitamin $\mathrm{B}_{12}$ destruction (therefore, the two vitamins should not be administered in combination), and augments amphetamine derivative and tricyclic antidepressant drug elimination by inhibiting their reabsorption in renal tubules $[28,29,56]$. Due to its chemical incompatibility, vitamin C should not be administered with drugs which have oxidizing properties [44]. By acidifying the urine, it can lead to the crystallization of urine excreted p-aminosalicylic acid and sulphonamides $[77,80]$. The use of high-dose vitamin $C$ yields false results in body fluid analyses performed with the use of methods based on redox reactions, e.g. determinations of bilirubin, glucose, or creatinine concentrations, and LDH or AspAT activity [1,29,73].

High doses of vitamin $\mathrm{C}$ hamper copper absorption and inhibit copper-containing ceruloplasmin and superoxide dismutase $(\mathrm{Cu}, \mathrm{Zn}-\mathrm{SOD})$ activities [15,73]. In contrast, they enhance iron absorption to the harmful degree in individuals with its excessive intestinal absorption, and also in those with increased blood iron concentration, and with hemochromatosis, sideroblastic anemia or thalassemia (where the symptoms exacerbate). Such doses can also lead to the release of that element from its tissue resources, i.e. stored in ferritin $[1,4,77]$. The excess unbound iron accumulates in the tissues and skin, irritates gastrointestinal mucosa, causes intoxication, and contributes to the prooxidant effects of vitamin C $[81,82]$.

Vitamin C-induced prooxidant effects can occur mainly due to the transition ion metal-reducing abilities of the vitamin, and the affected metals include among others iron and copper. In fact, reduced ions of the metals contribute to generating ${ }^{\circ} \mathrm{OH}$, which is a ROS particularly dangerous to the cells, and also of $\mathrm{O}_{2}{ }^{--}, \mathrm{H}_{2} \mathrm{O}_{2}$, and $\mathrm{HO}_{2}{ }^{\circ}$ $[15,73,77]$. Those reactions can repeat cyclically; they lead to the generation of large concentrations of the mentioned 
ROS which stimulate free radical reactions and show i.a. a mutagenic and neurotoxic activity. This is the reason why this vitamin should not be used along with iron and copper salts [24,28,77]. However, it has been found that vitamin $\mathrm{C}$ is able to act as prooxidant only at its low concentrations $[44,82]$.

The adverse effects of vitamin $\mathrm{C}$ can appear during the selective use of the vitamin in the prevention of lipid peroxidation-mediated diseases. The above vitamin prevents this process, especially with respect to LDL lipoproteins, but also decomposes previously formed lipid peroxides to more reactive 8- and 10-carbon aldehydes. These compounds act i.a. as mutagens, e.g. promote the reaction of 4,5-epoxy-2(E)-decenal with DNA, generating very mutagenic ethene-2'-deoxyadenosine residues [83]. Lipid peroxide formation is prevented by vitamin $\mathrm{E}$, which interrupts free radical-catalyzed peroxidative chain reactions. Therefore, the use of vitamins $\mathrm{C}$ and $\mathrm{E}$ together is not only important for their combined actions in lipid environment, but also makes the course of the aforementioned process impossible to take place [74].

Taking large doses of vitamin $\mathrm{C}$ may lead to vitamin $\mathrm{C}$ tolerance or even dependency (including pregnant womanmediated effect on fetus). The instantaneous withdrawal from such doses may result in deficiency symptoms, including scurvy; therefore, the doses must be lowered gradually to allow the body to accommodate the changes in delivery $[1,21,29]$. Also, vitamin $\mathrm{C}$ has a slightly stimulating activity, so its night-time taking is not recommended $[2,4]$. A range of adverse effects are induced by the oxidized form of vitamin $\mathrm{C}$ (formed in high concentrations when the reduced form of this vitamin is intensively, oxidative stress-dependently expended) $[15,44,84]$. It can lead to the inhibition of the transport of different substances and the impairment of some metabolic processes. This is due to its reactions with enzyme-SH groups (e.g. present in hexokinase, a key enzyme of glucose metabolism) and with other proteins $[77,85]$. The oxidized form of vitamin $\mathrm{C}$ is also able to damage erythrocytes (leading to hemolysis) and pancreatic $\beta$-cells, similarly as alloxan, well-known for that capability $[73,77,80]$.

\section{CONTROVERSIALITY OF RESULTS OF LARGE STUDIES EVALUATING THE HEALTH EFFECTS OF SUPPLEMENTATION WITH ANTIOXIDATIVE VITAMINS}

Numerous experimental studies on the action of antioxidative vitamins, performed on cell cultures and animals, as well as small short-term clinical trials relating to this action suggested that vitamins $\mathrm{A}, \mathrm{E}, \mathrm{C}$ and $\beta$-carotene have a beneficial effect on pathological states associated with oxidative stress. Based on those findings, optimistic implications were drawn that antioxidative vitamins used in high doses might play an important role in prevention and supportive treatment of diseases in which ROS and free radicals are involved [3-6].

This hypothesis, however, has not been confirmed by large-scale studies evaluating the health effects of longterm and high-dose antioxidative vitamin supplementation. These have been carried out since the 1990s on thousands of subjects from various risk groups, as well as potentially healthy volunteers, although less frequently on large populations of patients. The results of these investigations have turned out to be clearly controversial: contradictory in relation to results of experimental studies and small clinical trials, considerably differentiated and sometimes outright divergent. The expected favourable effects of vitamin supplementation has been dominated by the lack of ascertainment of these effects, and even increase in morbidity and/or mortality risk; also some surprising adverse effects appeared.

Presented below are the principal kinds of large studies which led to obtaining these results - ambiguous and distant from expectations. Due to a very great number of such investigations resulting, among others, from their various 
medical profiling, the scope of this presentation has been limited to two profiles connected with the most common and most severe diseases of current times: cancer of various organs and cardiovascular diseases.

\section{Selected studies targeted at cancer of various organs}

The large studies concerning this area are illustrated in the listing below based on a review by Bardia et al. [86], from which their most representative kinds were chosen; the listing comprises additionally three important studies not included in the Bardia et al. review. The descriptions are presented in a compact form, each incorporating the study cryptonym, country in which it was performed and the year of publication, number of participants, their sex ( $\mathrm{M}$ - men, $\mathrm{W}$ - women) and threats to their health, antioxidants used for supplementation, its duration, and the results (literature references to research descriptions by Bardia are presented in his quoted review). It should be added that the participants of these studies were receiving large but still non-toxic doses of antioxidative vitamins specified in subsequent descriptions. The prepared listing allows perceive only rare cases of favourable effects of vitamin supplementation.

- CCPS (China 1993): $29584 \mathrm{M}+\mathrm{W}$ with increased risk of various health disorders (a result of nutritional deficiency); vit. A, E, C, $\beta$-carotene, selenium, molybdenum, zinc (in various combinations) - 5 years; taking vit. $\mathrm{E}, \beta$-carotene and selenium decreased mortality from stomach cancer by $21 \%$ and from cancer overall by $13 \%$, as well as from cardiovascular diseases by $10 \%$; the joint effect was a decrease of all-cause mortality by $9 \%$ (other applied variants of supplementation were preventively ineffective);

- ATBC (Finland 1994): 29133 M with increased risk of cancer and/or cardiovascular diseases (smokers); vit. $E$ or $\beta$-carotene -6 years; taking vit. $E$ reduced cancer frequency of prostate by $34 \%$ and of large intestine by $16 \%$, but it increased by $25 \%$ for stomach cancer and by $9.5 \%$ for bladder cancer (also mortality from ischemic stroke dropped by $16 \%$ and from coronary artery disease by $5.5 \%$, but for hemorrhagic stroke it increased by $50 \%$ ); taking $\beta$-carotene increased frequency of stomach cancer by $25 \%$, of prostate cancer by $23 \%$ and of lung cancer by $18 \%$ (there were no effects for cardiovascular diseases);

— PHS I (US 1996): $22071 \mathrm{M}$ with average risk of cancer; $\beta$-carotene - 12 years; there were no preventive effects for cancer overall, but there were no harmful effects either (the same was found for cardiovascular diseases);

- WHS (US 1999): 39876 W with average risk of cancer; $\beta$-carotene -2 years, continuation with vit. $\mathrm{E}$ (2005) - 10 years; for both applied antioxidants the results were analogous to the PHS I study (without cardiovascular diseases, which were not taken into account);

- SU.VI.MAX (France 2004): 13017 M+W with average risk of cancer; vit. E, C, $\beta$-carotene, selenium and zinc (taken together) - 7.5 years; decreased frequency of cancer overall by $27.5 \%$ and all-cause mortality by $35 \%$, but only in $\mathrm{M}$ and not in $\mathrm{W}$;

— PLCO (US 2006) [87]: $29361 \mathrm{M}$ with intensified risk of prostate cancer; vit. E- 8 years; decreased risk of development of advanced prostate cancer by $70 \%$;

— PHS II (US 2009) [88]: 14641 M with intensified risk of prostate cancer; vit. E and C (taken together) 10 years; for both antioxidants there were no preventive effects;

- SELECT (US, Canada, Puerto Rico 2009) [89]: $35533 \mathrm{M}$ with intensified risk of prostate cancer; vit. E and/or selenium - 7 years; both antioxidants were preventively ineffective.

\section{Selected studies targeted at cardiovascular diseases}

The listing of relevant large studies presented below is based on review by Ueda and Yasunari [90]; our listing 
includes additionally two important studies not included in the Ueda and Yasunari review. As in the previous subchapter, the descriptions are given a compact form, with the same arrangement also with addition of the abbreviations of diseases present in the descriptions: CAD - coronary artery disease, CVD - cardiovascular disease, MI - myocardial infarction (literature references to research descriptions by Ueda and Yasunari are presented in their quoted review). The participants in these studies were receiving large but still non-toxic doses of antioxidative vitamins specified in the subsequent descriptions. As it can be seen from the presented listing, the observed effects of the supplementation were seldom entirely favourable.

- HPS (US 1993): 39910 M with risk of CAD; vit. $\mathrm{E}$ or $\mathrm{C}$ or $\beta$-carotene -4 years; taking vit. $\mathrm{E}$ decreased risk of CAD by $37 \%$ (vit. $\mathrm{C}$ and $\beta$-carotene were preventively ineffective);

- NHS (US 1993): 87245 W with risk of CAD; vit. E 8 years; drop of CAD risk by $41 \%$;

- CHAOS (UK 1996): 2002 M+W with CAD; vit. E 1.4 years; drop of nonfatal MI frequency by $77 \%$ without changes for fatal MI, but increase (though insignificant) of mortality from CVD;

- EPESE (US 1996): $11178 \mathrm{M}+\mathrm{W}$ with risk of CAD; multivitamins + vit. $\mathrm{E}$ and $\mathrm{C}-9$ years; decrease of mortality from CAD by $47 \%$ and all-cause mortality by $37 \%$;

- IWHS (US 1996): $34387 \mathrm{~W}$ with risk of CAD; vit. E, $\mathrm{C}$ and carotenoids (taken together) - 6 years; drop of CAD risk by $62 \%$, but increase (though insignificant) of breast cancer risk;

- GISSI (Italy 1999): 11324 M+W with history of MI; vit. E and/or n-3 polyunsaturated fatty acids (PUFA) 3.5 years; vit. E did not bring health benefits (as opposed to positive effect of PUFA);

- CARET (US 1996) [91]: $18314 \mathrm{M}+\mathrm{W}$ with increased risk of CVD and/or cancer (smokers or working with asbestos); vit. $\mathrm{E}$ and $\beta$-carotene -1.75 years; increase of MI risk by $26 \%$ and death from CVD by $55 \%$, as well as increased incidence of lung cancer by $28 \%$; joint effect was an increase of all-cause mortality by $17 \%$ (for ethical reasons, the study was stopped);

- WACS (US 2007) [92]: $8171 \mathrm{~W}$ with risk of CVD; vit. $\mathrm{E}, \mathrm{C}$ and $\beta$-carotene (taken separately or together) - 9.4 years; none of the supplementation variants brought the preventive effects.

In the above listing, three large studies were omitted: HOPE, PPP and MRC/BHF, as their aim was not to test the effects of supplementation solely with antioxidative vitamins, but to control the potential for their administration in supporting the action of some medicines used in cardiovascular diseases therapy: ramipril, aspirin and simvastatin, in order of the studies mentioned above (no favourable effect of the applied vitamins was noted).

\section{Meta-analysis of results of studies}

\section{on the effectiveness of antioxidative vitamin}

\section{administration in the prevention of various diseases}

The lack of unequivocal results from numerous studies evaluating the health effectiveness of long-term supplementation with large doses of antioxidative vitamins (vide examples given above) was the inspiration for this summary through the meta-analyses. However, there were considerable differences in the choices of source data and their modes of processing by particular authors. Owing to this, the results were found to be largely incoherent; they were not only insufficient to eliminate the doubts connected with vitamin supplementation, but even increased them.

The largest number of these meta-analyses were performed by Bjelakovic and Gluun with their team. Based on the results of the studies selected from databases and literature, they evaluated the health effectiveness of the administration of vitamins A, E, C, $\beta$-carotene, and selenium (in combinations) in prevention of various diseases. 
The most attention was paid to digestive system disorders: stomach and intestine cancer [93-96], colorectal adenoma [97], various other gastrointestinal disorders [98,99], and liver diseases [100]. However, the range of works included also other types of diseases: cardiovascular, nervous, osteoarticular, renal, endocrine, ocular, dermal, and nonorgan-specific $[98,99]$.

The resulting whole of their meta-analyses delivered only negative findings. With respect to digestive system diseases, the researchers did not find evidence of any preventive action by antioxidative vitamins, and regarding stomach and intestine cancer they even suggested an increase of all-cause mortality caused by intake of these vitamins (selenium was regarded as not sufficiently examined). For all other diseases they also found lack of evidence for preventive effectiveness of the above listed antioxidants and came to the same conclusions concerning the increase of all-cause mortality: from vitamin A by $16 \%$, from vitamin E by 4-7\% and from $\beta$-carotene by 7\% [99]. According to these authors, the usage of vitamin $\mathrm{C}$ or selenium instead does not have either a favourable or a harmful effect, as can be seen from the data.

The meta-analyses by Bjelakovic et al. leading to such disturbing conclusions received a number of negative appraisals, based on the opinions of various experts. A multidirectional criticism of their meta-analyses was given by Levin [101], referring to Stampfer (nutrition and epidemiology expert) and Barry (biostatistics expert). His main objections included: during the selection of source data, the omission of over 400 studies with the use of the a/m antioxidants where no deaths occurred; equivalent treating of studies including potentially healthy subjects with those including sick persons with various chronic diseases (taking medicines used in their therapy), with large differences between doses of applied antioxidants and incomparable times of administration - from one month to 12 years; non-consideration of death causes in the selected studies, with lack of evidence for antioxidants being the cause of death (what is supported by the fact that only 4 cases of death caused by vitamin overdose were noted in the US in 2003 [102]). Nearly the same objections were raised by Wilson [103], referring also to Stampfer as well as Shao (biochemistry of nutrition expert), with addition further critical remarks: ignoring in the meta-analyzes those studies which confirmed the benefit of applying the antioxidative supplements, and focusing on mortality and secondary prevention (in the sick persons) instead of on primary prevention (in potentially healthy subjects).

Completely different from Bjelakovic et al. were the results of thematically analogous meta-analyses made by other researchers. Indeed, Knekt et al. [104] found vitamin $\mathrm{E}$ and carotenoids lacked efficacy in the prevention of cardiovascular diseases, but they noted a significant decrease in frequency of coronary artery disease and other serious cardiac events in sick persons supplemented with large doses of vitamin C (> $700 \mathrm{mg} / \mathrm{d})$. A meta-analysis by Wright et al. [105] showed, however, that a long-term intake rich in dietary and/or supplemental vitamin E significantly reduces mortality from coronary artery disease and from ischemic stroke, as well as all-cause mortality. Ye and Song [106] noted a decreased risk of coronary artery disease through a regular intake of dietary and/or supplemental vitamin E, C and $\beta$-carotene. Regarding oncology, a meta-analysis by Myung et al. [107] affirmed the preventive effects of supplementation with vitamins $\mathrm{E}, \mathrm{C}$ and $\beta$-carotene against cervical neoplasms, including invasive cancer.

At the end of this review of meta-analyses, it is worth referring to a recently published work, which questions credibility of the aforementioned alarmist results that have been earlier reported by Bjelakovic et al. It is a reanalysis of two meta-analyses by these researchers [98,99] made by Biesalski et al. [108] using the same dataset. This reanalysis has led to statement contradictory to the above results that $36 \%$ of source studies revealed beneficial effects of supplementation with antioxidants, $60 \%$ null 
effects (neither positive, not negative), and only $4 \%$ harmful effects. The above example proves the necessity of care when interpreting meta-analyses, because they are purely secondary statistical studies, with the quality of the results being dependent on reliability of their authors. Therefore, it is indispensable to continue large studies, but carefully designed and standardized, evaluating the health effectiveness of long-term supplementation based around the use of well-chosen doses of various combinations of antioxidative vitamins.

\section{SUMMARY}

In summary, it should be emphasized that antioxidant vitamins do not act as independent factors, but they constitute a part of a complex system called the systemic antioxidant barrier [15]. Therefore, additional substances with similar action profile may be essential to achieve the desired therapeutic goals. In the body, vitamin $\mathrm{C}$ closely cooperates e.g. with vitamin $\mathrm{E}$. The latter protects vitamin A from oxidation in the alimentary tract and co-works with $\beta$-carotene and selenium $[1,39,74]$. Antioxidant vitamins also act synergistically with different bioflavonoids $[44,56]$. Thus, large doses of individual antioxidant vitamins with the use of their synthetic preparations can lead to the disruption or abrogation of other ROS- and free radicalneutralizing mechanisms. As a result, antioxidant vitamininduced damage is sometimes more serious. It might be less harmful if this-type vitamin therapy was not ever applied [15].

\section{REFERENCES}

1. Hamrick I, Counts SH. Vitamin and mineral supplements. Wellness Prevent 2008;35:729-47.

2. Coates PM, Blackman MR, Cragg GM, Levine M, Moss J, White JD. Encyclopedia of dietary supplements. New York: Marcel Dekker; 2005.
3. Swami HM, Thakur JS, Bhatia SP. Impact of mass supplementation of vitamin A. Indian J Pediatr 2007;74:443-7.

4. Assouline S, Miller WH. High-dose vitamin C therapy. Can Med Assoc J 2006;174:956-7.

5. Scientific Committee on Food (SCF). Opinion of the Scientific Committee on Food on the tolerable upper intake level of vitamin E. SCF/CS/NUT/UPPLEV/31. Brussels: Commission of the European Communities; 2003.

6. Scientific Committee on Food (SCF). Opinion of the Scientific Committee on Food on the tolerable upper intake level of beta-carotene. SCF/CS/NUT/UPPLEV/37. Brussels: Commission of the European Communities; 2000.

7. Herbert V. Underreporting of dietary supplements to health-care providers does great harm. Mayo Clin Proc 1999;74:531-2.

8. Goodman GE. Assessing toxicity in cancer chemoprevention trials: the other side of the coin. Cancer Prev Res 2008;1: 499-502.

9. Huang HY, Caballero B, Chang S, Alberg A, Semba R, Schneyer C, et al. Multivitamin/mineral supplements and prevention of chronic disease. Evid Rep Technol Assess 2006;(139):1-117.

10. Combs GF. The vitamins - fundamental aspects in nutrition and health. Burlington: Elsevier Academic Press; 2008.

11. Semba RD. Vitamin $A$ as anti-infective therapy. J Nutr 1999;129:783-91.

12. Valko M, Leibfritz D, Moncol J, Cronin MT, Mazur M, Telser J. Free radicals and antioxidants in normal physiological functions and human disease. Int J Biochem Cell Biol 2007;39:44-84.

13. Benzie IFF. Evolution of dietary antioxidants. Comp Biochem Physiol Part A, Mol Integr Physiol 2003;136:113-26.

14. Rutkowski M, Grzegorczyk K. Vitamins with antioxidant action: a general characterisation. Part I : Vitamin A. Farm Pol 1998;54:739-43 [in Polish].

15. Lane N. Oxygen: the molecule that made the world. New York: Oxford University Press; 2004.

16. Dragnev KH, Rigas JR, Dmitrovsky E. The retinoids and cancer prevention mechanisms. Oncologist 2000;5:361-8. 
17. Clarke N, Germain P, Altucci L, Gronemeyer H. Retinoids potential in cancer prevention and therapy. Exp Rev Mol Med 2004;6:1-23.

18. Stanner SA, Hughes J, Kelly CN, Buttriss J. A review of the epidemiological evidence for the "antioxidant hypothesis". Publ Health Nutr 2004;7:407-22.

19. Lamson DW, Brignall MS. Antioxidants in cancer therapy their actions and interactions with oncologic therapies. Altern Med Rev 1999;4:304-29.

20. Food and Nutrition Board, Institute of Medicine. Vitamin A. In: Dietary reference intakes for vitamin A, vitamin $K$, arsenic, boron, chromium, copper, iodine, iron, manganese, molybdenum, nickel, silicon, vanadium, and zinc. Washington: National Academy Press; 2001. p. 82-161.

21. Halliwell B. Establishing the significance and optimal intake of dietary antioxidants. Nutr Rev 1999;57:104-13.

22. Block KI, Koch AC, Mead MN, Tothy PK, Newman RA, Gyllenhaal C. Impact of antioxidant supplementation on chemotherapeutic toxicity: a systematic review of the evidence from randomized controlled trials. Int J Cancer 2008;123:1227-39.

23. Temple BR. Vitamin toxicity. In: Dart RC, editor. Medical toxicology. Philadelphia: Lippincott Williams and Wilkins; 2004. p. 1017-24.

24. Expert Group on Vitamins and Minerals. Risk assessments. In: Safe upper levels for vitamins and minerals. London: Food Standards Agency; 2003. p. 100-53.

25. Kapil U. Time to stop giving indiscriminate massive doses of synthetic vitamin $A$ to Indian children. Public Health Nutr 2009;12:285-6.

26. McClure SC, Chauncey K, Nipp RD. Vitamin A use today and its potential toxicities. Clin Geriatr 2010;18:41-5.

27. Penniston KL, Tanumihardjo SA. The acute and chronic toxic effects of vitamin A. Am J Clin Nutr 2006;83:191-201.

28. Rogovik AL, Vohra S, Goldman RD. Safety considerations and potential interactions of vitamins: should vitamins be considered drugs? Ann Pharmacother 2010;44:311-24.

29. Reuter HD. Vitamins. In: Aronson JK, editor. Side effects of drugs. Annual 27. Amsterdam: Elsevier BV; 2004. p. 405-13.
30. DiGiovanna JJ. Fracturing support for the role of systemic retinoid therapy as a cause of bone demineralization. Arch Dermatol 2010;146:551-3.

31. Ribaya-Mercado JD, Blumber JB. Vitamin A: is it a risk factor for osteoporosis and bone fracture? Nutr Rev 2007;65:425-38.

32. Melhus H, Michaëlsson K, Kindmark A, Bergström R, Holmberg $\mathrm{L}$, Mallmin $\mathrm{H}$, et al. Excessive dietary intake of vitamin $A$ is associated with reduced bone mineral density and increased risk for hip fracture. Ann Intern Med 1998;129:770-8.

33. Promislow JH, Goodman-Gruen D, Slymen DJ, BarrettConnor E. Retinol intake and bone mineral density in the elderly: the Rancho Bernardo Study. J Bone Miner Res 2002;17:1349-58.

34. Ballew C, Galuska D, Gillespie C. High serum retinyl esters are not associated with reduced bone mineral density in the Third National Health And Nutrition Examination Survey, 1988-1994. J Bone Miner Res 2001;16:2306-12.

35. Leo MA, Lieber CS. Alcohol, vitamin A, and $\beta$-carotene: adverse interactions, including hepatotoxicity and carcinogenicity. Am J Clin Nutr 1999;69:1071-85.

36. Rimm EB, Stampfer MJ. Antioxidants and chronic disease: evidence from observational epidemiology. Bibl Nutr Dieta 2001;55:80-91.

37. Azais-Braesco V, Pascal G. Vitamin A in pregnancy: requirements and safety limits. Am J Clin Nutr 2000;71:1325S-33S.

38. Miller RK, Hendricks AG, Mills JL, Hummler H, Wiegand UW. Periconceptional vitamin A use: how much is teratogenic? Reprod Toxicol 1998;12:75-88.

39. Bendich A. What have we learned about the „biological actions of beta-carotene"? J Nutr 2004;134:125S-30S.

40. Rutkowski M, Grzegorczyk K. What should be known nowadays about $\beta$-carotene and other carotenoids? Farm Pol 2002;58:97-105 [in Polish].

41. Tanumihardjo SA. Factors influencing the conversion of carotenoids to retinol: bioavailability to bioconversion to bioefficacy. Int J Vit Nutr Res 2002;72:40-5.

42. Young AJ, Lowe GM. Antioxidant and prooxidant properties of carotenoids. Arch Biochem Biophys 2001;385:20-7. 
43. Krinsky NI. Carotenoids as antioxidants. Nutrition 2001;17:815-7.

44. Schwedhelm E, Maas R, Troost R, Boger RH. Clinical pharmacokinetics of antioxidants and their impact on systemic oxidative stress. Clin Pharmacokinet 2003;42:437-59.

45. Mayne ST. Antioxidant nutrients and chronic disease. J Nutr 2003;133:933S-940S.

46. Adly AAM. Oxidative stress and disease: an updated review. Res J Immunol 2010;3, 129-45.

47. Borel P, Drai J, Faure H, Fayol V, Galabert C, Laromiguiere $\mathrm{M}$, et al. Recent knowledge about intestinal absorption and cleavage of carotenoids. Ann Biol Clin (Paris) 2005;63: $165-77$.

48. Food and Nutrition Board, Institute of Medicine. Vitamin C. Vitamin E. $\beta$-Carotene and Other Carotenoids. In: Dietary Reference Intakes for Vitamin C, Vitamin E, Selenium, and Carotenoids. Washington: National Academy Press; 2000. p. $95-185,186-283,325-82$.

49. Paolini M, Abdel-Rahman SZ, Cantelli-Forti G. Chemoprevention or antichemoprevention? a salutary warning from the $\beta$-carotene experience. J Natl Cancer Inst 2001;93:1110-11.

50. Woutersen RA, Wolterbeek AP, Appel MJ, van den Berg H, Goldbohm RA, Feron VJ. Safety evaluation of synthetic betacarotene. Crit Rev Toxicol 1999;29:515-42.

51. Is it true that antioxidant supplements such as beta carotene, vitamin A and vitamin E can raise my risk of death? [editorial]. Duke Med Health News 2009;15:12.

52. Satia JA, Littman A, Slatore CG, Galanko JA, White E. Long-term use of $\beta$-carotene, retinol, lycopene, and lutein supplements and lung cancer risk: results from the VITamins And Lifestyle (VITAL) Study. Am J Epidemiol 2009;169:815-28.

53. Gallicchio L, Boyd K, Matanoski G, Tao X, Chen L, Lam TK, et al. Carotenoids and the risk of developing lung cancer: a systematic review. Am J Clin Nutr 2008;88:372-83.

54. Tanvetyanon T, Bepler G. Beta-carotene in multivitamins and the possible risk of lung cancer among smokers versus former smokers: a meta-analysis and evaluation of national brands. Cancer 2008;113:150-7.
55. Mayne ST, Redlich CA, Cullen MR. Dietary vitamin A and prevalence of bronchial metaplasia in asbestos-exposed workers. Am J Clin Nutr 1998;68:630-5.

56. Stargrove MB, Treasure J, McKee DL. Herb, nutrient, and drug interactions: clinical implications and therapeutic strategies. St. Louis: Mosby Elsevier; 2008.

57. Colombo ML. An update on vitamin E, tocopherol and tocotrienol: perspectives. Molecules 2010;15:2103-13.

58. Schneider C. Chemistry and biology of vitamin E. Mol. Nutr Food Res 2005;49:7-30.

59. Rutkowski M, Grzegorczyk K, Chojnacki J, Kędziora J. Antioxidative properties of vitamin $E$ as a new approach to its applications in therapy. Pol Merk Lek 2006;20:609-14 [in Polish].

60. Traber MG, Atkinson J. Vitamin E, antioxidant and nothing more. Free Radic Biol Med 2007;43:4-15.

61. Roberts LJ, Oates JA, Linton MF, Fazio S, Meador BP, Gross MD, et al. The relationship between dose of vitamin $E$ and suppression of oxidative stress in humans. Free Radic Biol Med 2007;43:1388-93.

62. Roberts LJ, Traber MG, Frei B. Vitamins $E$ and $C$ in the prevention of cardiovascular disease and cancer in men. Free Radic Biol Med 2009;46:1558.

63. Meydani SN, Meydani M, Blumberg JB, Leka LS, Pedrosa M, Diamond R, et al. Assessment of the safety of supplementation with different amounts of vitamin $E$ in healthy older adults. Am J Clin Nutr 1998;68:311-8.

64. Rota S, McWilliam NA, Baglin TP, Byrne CD. Atherogenic lipoproteins support assembly of the prothrombinase complex and thrombin generation: modulation by oxidation and vita$\min$ E. Blood 1998;91:508-15.

65. Pearson P, Lewis SA, Britton J, Young IS, Fogarty A. The pro-oxidant activity of high-dose vitamin E supplements in vivo. BioDrugs 2006;20:271-3.

66. Burkitt MJ. A critical overview of the chemistry of copper-dependent low density lipoprotein oxidation: roles of lipid hydroperoxides, alpha-tocopherol, thiols, and ceruloplasmin. Arch Biochem Biophys 2001;394:117-35. 
67. Anonymous. Scientific Opinion of the Panel on Food Additives, Flavourings, Processing Aids and Material in Contact with Food on a request from the Commission on mixed tocopherols, tocotrienol tocopherol and tocotrienols as sources for vitamin E. EFSA J 2008;640:1-34.

68. Brown BG, Zhao XQ, Chait A, Fisher LD, Cheung MC, Morse JS, et al. Simvastatin and niacin, antioxidant vitamins, or the combination for the prevention of coronary disease. N Engl J Med 2001;345:1583-92.

69. Brion LP, Bell EF, Raghuveer TS. Vitamin E supplementation for prevention of morbidity and mortality in preterm infants. Cochrane Database Syst Rev 2003;(4):CD003665.

70. Oguntibeju OO. The biochemical, physiological and therapeutic roles of ascorbic acid. Afr J Biotechnol 2008;7:4700-5.

71. Jacob RA. Vitamin C. In: Shils ME, Olson JA, Shike M, Ross AC, editors. Modern nutrition in health and disease. Baltimore: Williams \& Wilkins; 1999. p. 467-82.

72. Padayatty S, Katz A, Wang Y, Eck P, Kwon O, Lee JH, et al. Vitamin $C$ as an antioxidant - evaluation of its role in disease prevention. J Am Coll Nutr 2003;22:18-35.

73. Rutkowski M, Grzegorczyk K. Vitamins with antioxidant action: a general characterisation. Part III : Vitamin C. Farm Pol 1999;55:74-9 [in Polish].

74. Hamilton IM, Gilmore WS, Benzie IF, Mulholland CW, Strain JJ. Interactions between vitamins $C$ and $E$ in human subjects. Br J Nutr 2000;84:261-7.

75. Naidu KA. Vitamin $C$ in human health and disease is still a mystery? An overview. Nutr J 2003;2:7-23.

76. Weeks BS, Perez PP. A novel vitamin C preparation enhances neurite formation and fibroblast adhesion and reduces xenobiotic-induced T-cell hyperactivation. Med Sci Monit 2007;13:51-8.

77. Halliwell B. Vitamin C: poison, prophylactic or panacea? Trends Biochem Sci 1999;24:255-9.

78. Choi HK, Xiang G, Curhan G. Vitamin C intake and the risk of gout in men. Arch Intern Med 2009;169:502-7.
79. Taylor EN, Stampfer MJ, Curhan GC. Dietary factors and the risk of incident kidney stones in men - new insights after 14 years of follow-up. J Am Soc Nephrol 2004;15:3225-32.

80. Auer BL, Auer D, Rodgers AL. Relative hyperoxaluria, crystalluria and haematuria after megadose ingestion of vitamin $C$. Eur J Clin Invest 1998;28:695-700.

81. Cook JD, Reddy MB. Effect of ascorbic acid intake on nonheme-iron absorption from a complete diet. Am J Clin Nutr 2001;73:93-8.

82. Carr A, Frei B. Does vitamin $C$ act as a pro-oxidant under physiological conditions? FASEB J 1999;13:1007-24.

83. Lee SH, Oe T, Blair IA. Vitamin C-induced decomposition of lipid hydroperoxides to endogenous genotoxins. Science 2001;292:2083-6.

84. Wilson JX. The physiological role of dehydroascorbic acid. FEBS Lett 2002;527:5-9.

85. Fiorani M, DeSanctis R, Scarlatti F, Vallorani L, DeBellis R, Serafini G, et al. Dehydroascorbic acid irreversibly inhibits hexokinase activity. Mol Cell Biochem 2000;209:145-53.

86. Bardia A, Tleyjeh IM, Cerhan JR, Sood AK, Limburg PJ, Erwin PJ, et al. Efficacy of antioxidant supplementation in reducing primary cancer incidence and mortality: systematic review and meta-analysis. Mayo Clin Proc 2008;83:23-34.

87. Kirsh VA, Hayes RB, Mayne ST, Chatterjee N, Subar AF, Dixon LB, et al. PLCO Trial. Supplemental and dietary vitamin E, beta-carotene, and vitamin C intakes and prostate cancer risk. J Natl Cancer Inst 2006;98:245-54.

88. Gaziano JM, Glynn RJ, Christen WG, Kurth T, Belanger C, MacFadyen J, et al. Vitamins $E$ and $C$ in the prevention of prostate and total cancer in men; the Physicians' Health Study II Randomized Controlled Trial. JAMA 2009;301:52-62.

89. Lippman SM, Klein EA, Goodman PJ, Lucia MS, Thompson IM, Ford LG, et al. Effect of selenium and vitamin $E$ on risk of prostate cancer and other cancers: the Selenium and Vitamin E Cancer Prevention Trial (SELECT). JAMA 2009;301:39-51.

90. Ueda S, Yasunari K. What we learnt from randomized clinical trials and cohort studies of antioxidant vitamin? Focus on 
vitamin E and cardiovascular disease. Curr Pharm Biotechnol 2006;7:69-72.

91. Omenn GS, Goodman GE, Thornquist MD, Balmes J, Cullen MR, Glass A, et al. Effects of a combination of beta carotene and vitamin A on lung cancer and cardiovascular disease. N Engl J Med 1996;334:1150-5.

92. Cook NR, Albert CM, Gaziano JM, Zaharris E, MacFadyen J, Danielson E, et al. A randomized factorial trial of vitamins $C$ and $E$ and beta carotene in the secondary prevention of cardiovascular events in women. Results from the Women's Antioxidant Cardiovascular Study. Arch Intern Med 2007;167:1610-8.

93. Bjelakovic G, Nikolova D, Simonetti RG. Antioxidants for preventing gastrointestinal cancers (protocol for a Cochrane Review). The Cochrane Library, Issue 2, 2003. Oxford: Update Software.

94. Bjelakovic G, Nikolova D, Simonetti RG, Gluud C. Antioxidant supplements for preventing gastrointestinal cancers. Cochrane Database Syst Rev 2004;(4):CD004183.

95. Bjelakovic G, Nikolova D, Simonetti RG, Gluud C. Antioxidant supplements for prevention of gastrointestinal cancers: a systematic review and meta-analysis. Lancet 2004;364: 1219-28.

96. Bjelakovic G, Nikolova D, Simonetti RG, Gluud C. Systematic review: primary and secondary prevention of gastrointestinal cancers with antioxidant supplements. Aliment Pharmacol Ther 2008;28:689-703.

97. Bjelakovic G, Nagorni A, Nikolova D, Simonetti RG, Bjelakovic M, Gluud C. Meta-analysis: antioxidant supplements for primary and secondary prevention of colorectal adenoma. Aliment Pharmacol Ther 2006;24:281-91.

98. Bjelakovic G, Nikolova D, Gluud LL, Simonetti RG, Gluud C. Mortality in randomized trials of antioxidant supplements for primary and secondary prevention: systematic review and meta-analysis. JAMA 2007;297:842-57.

99. Bjelakovic G, Nikolova D, Gluud LL, Simonetti RG, Gluud C. Antioxidant supplements for prevention of mortality in healthy participants and patients with various diseases. Cochrane Database Syst Rev 2008;(2):CD007176.
100. Bjelakovic G, Gluud LL, Nikolova D, Bjelakovic M, Nagorni A, Gluud C. Meta-analysis: antioxidant supplements for liver diseases - the Cochrane Hepato-Biliary Group. Aliment Pharmacol Ther 2010;32:356-67.

101. Levin NE. Antioxidant confusion. Ann Intern Med [publ. on-line] 2007 Jul 11 [cited 2012 March 30]. Available from URL: http://www.annals.org/content/147/4/271/ reply\#annintmed_el_21702.

102. Watson WA, Litovitz TL, Klein-Schwartz W, Rodgers GC, Youniss J, Reid N, et al. 2003 annual report of the American Association of Poison Control Centers Toxic Exposure Surveillance System. Am J Emerg Med 2004;22:335-404.

103. Wilson NS. A challenge to the criticisms of nutritional therapy. Lainst Clin [publ. on-line] 2010 Sep 10 [cited 2012 March 30]. Available from URL: http://www.leinsterclinic.ie/a-challenge-to-the-criticisms-of-nutritionaltherapy.

104. Knekt P, Ritz J, Pereira MA, O'Reilly EJ, Augustsson K, Fraser GE, et al. Antioxidant vitamins and coronary heart disease risk: a pooled analysis of 9 cohorts. Am J Clin Nutr 2004;80:1508-20.

105. Wright ME, Lawson KA, Weinstein SJ, Pietinen P, Taylor PR, Virtamo J, et al. Higher baseline serum concentrations of vitamin $E$ are associated with lower total and cause-specific mortality in the Alpha-Tocopherol, BetaCarotene Cancer Prevention Study. Am J Clin Nutr. 2006;84:1200-7.

106. Ye Z, Song H. Antioxidant vitamins intake and the risk of coronary heart disease: meta-analysis of cohort studies. Eur J Cardiovasc Prev Rehabil 2008;15:26-34.

107. Myung SK, Ju W, Kim SC, Kim H; Korean Meta-analysis (KORMA) Study Group. Vitamin or antioxidant intake (or serum level) and risk of cervical neoplasm: a meta-analysis. BJOG 2011;118:1285-91.

108. Biesalski HK, Grune T, Tinz J, Zöllner I, Blumberg JB. Reexamination of a meta-analysis of the effect of antioxidant supplementation on mortality and health in randomized trials. Nutrients 2010;2:929-49.

This work is available in Open Access model and licensed under a Creative Commons Attribution-NonCommercial 3.0 Poland License - http://creativecommons.org/ licenses/by-nc/3.0/pl/deed.en. 